\title{
COMENTARIOS A LA REGULACIÓN DEL CONTRATO DE SEGURO EN EL PROYECTO DE CÓDIGO CIVIL DE LA UNIVERSIDAD NACIONAL DE COLOMBIA*
}

\section{COMMENTS ON THE REGULATION OF THE INSURANCE CONTRACT IN THE DRAFT CIVIL CODE PROJECT OF THE NATIONAL UNIVERSITY OF COLOMBIA}

\author{
FERNANDO PALACIOS SÁNCHEZ** \\ Fecha de recepción: 18 de agosto 2020 \\ Fecha de aceptación 20 de noviembre 2020 \\ Disponible en línea: 30 de diciembre 2020
}

Para citar este artículo/To cite this article

Palacios Sánchez, Fernando. Comentarios a la regulación del contrato de seguros en el proyecto de Código Civil de la Universidad Nacional de Colombia, 53 Rev.Ibero-Latinoam. Seguros, 39-54 (2020). https://doi.org/10.11144/Javeriana.ris53.crcs

doi:10.11144/Javeriana.ris53.crcs

\footnotetext{
* Artículo de reflexión.

** Especialista en Derecho de Seguros de la Universidad Javeriana, abogado de la misma Universidad, hizo el curso de Seguros Generales y de Seguros de Vida en el Centro Suizo de Formación Aseguradora "SITC". Es Asesor de Procesos Académicos de la especialización en Seguros y Seguridad Social de la Universidad de La Sabana, profesor de Derecho de Seguros de la misma. Miembro de la Asociación Colombiana de Derecho de Seguros, ACOLDESE-AIDA.Contacto: fernando.palacios_cont@unisabana.edu.co ferpal48@ hotmail.com.
} 


\title{
RESUMEN
}

El presente trabajo tiene por objeto examinar algunos aspectos relevantes sobre la regulación del contrato de seguro que contempla el proyecto de un nuevo Código Civil, presentado por la Universidad Nacional de Colombia. Entre los hallazgos del estudio, se encontró que el proyecto es unilineal en orden a la protección del asegurado, que contiene aspectos positivos, como las pautas para interpretar el contrato de seguro y la ampliación de los medios probatorios para demostrar su existencia, pero, a la vez, tiene otros temas que deben revisarse, como la definición del contrato de seguro y la eliminación de las características de dicho contrato. El trabajo identifica unos y otros y propone soluciones sobre los temas que causan inquietud.

Palabras clave: Protección al asegurado, definición, interpretación, características, contrato de seguro.

\begin{abstract}
The purpose of this work is to examine some relevant aspects of the regulation of the insurance contract included in the project of a new Civil Code, which were presented by the National University of Colombia. It was found that the project is unilinear in relation to the insured client, which leads to positive aspects such as the guidelines to interpret the insurance contract and the expansion of the evidence to prove its existence, but at the same time, it represents challenges that must be reviewed like the definition of the insurance contract and the elimination of the characteristics of said contract. The work identifies existing challenges and proposes solutions to issues that are currently a cause for concern.
\end{abstract}

Keywords: Insured protection, definition, interpretation, characteristics, insurance contract. 


\section{PRINCIPIOS COMUNES A LOS SEGUROS TERRESTRES}

\subsection{Definición y atributos del contrato de seguro}

El título V del libro IV de Código de Comercio no trae una definición sobre el Contrato de Seguro, dice al respecto el Maestro Ossa:

"No define la ley el contrato de seguro. Por considerar, sin duda, que es tarea laboriosa y arriesgada, dada la innegable complejidad de esta institución jurídica, ha preferido hacer caso omiso de ella, librarla al juicio de la doctrina, al ejercicio académico de los expositores y limitarse, como veremos, a ofrecer un esquema jurídico del contrato a través de algunos de sus preceptos medulares"1.

El proyecto sustituye el art. 1036 que contiene las características del contrato de seguro y lo reemplaza por la siguiente definición del contrato de seguro:

"Por el contrato de seguro una parte, asegurador, debidamente autorizado para ello con arreglo a las leyes y reglamentos, se obliga a pagar una indemnización, un capital o, en general, una determinada prestación convenida, a un asegurado, o a un beneficiario, si ocurre un riesgo a la persona, a los bienes, a cambio de una prima a cargo de la otra parte, el tomador".

Debemos discrepar, con todo respeto, de dos aspectos que no podemos compartir: a) En realidad los riesgos "no ocurren," sino que, al materializarse, se convierten en siniestros, tal como lo señala el propio proyecto en su art. 1444: "se denomina siniestro la realización del riesgo asegurado." Y en el art. 1425, de acuerdo con el cual: "El riesgo es el suceso incierto que no depende exclusivamente de la voluntad del tomador, del asegurado o del beneficiario, y cuya realización da origen a la obligación del asegurador." Ambos artículos son iguales a los que contiene el título V vigente, lo que nos hace pensar que se trata de un lapsus que debe corregirse. b) Por lo dicho, la expresión "si ocurre un riesgo" utilizada en la definición, quiere decir "si ocurrió un siniestro". Ciertamente muchos siniestros "ocurren" sin participación del ser humano. Son hechos fortuitos, productos del azar. Imprevisibles e irresistibles. Son ejemplos de éstos los terremotos, huracanes, tsunamis, anegaciones, tornados, incendios, etc., pero, hay otros que obedecen o son producto de la conducta humana. No son fortuitos. Nos referimos a los siniestros en los seguros de responsabilidad civil que cubren los perjuicios que causa el ser humano por su actividad, en éstos no es que "acaezca", u "ocurra" un siniestro como los descritos, pues el siniestro deriva de una conducta culposa del asegurado que debió preverlo, o que, habiéndolo previsto, confió por temeridad o por negligencia que podía evitarlo. En resumen, en la definición que encabeza el nuevo título sobre regulación al contrato de seguro no cabe todo lo definido, dado que deja por fuera los seguros de responsabilidad civil.

Similar crítica se hacía al art. 636 del Código de Comercio de 1887 que decía: "Se entiende por riesgo la eventualidad de todo caso fortuito que puede causar la pérdida

${ }^{1}$ Ossa J. (1991) Teoría general del seguro. El contrato. Bogotá: Temis, 2 edición, p. 1. 
o deterioro de los objetivos asegurados". Cita al respecto el profesor Carlos Ignacio JARAMILLO un aparte de la exposición de motivos del año 1958:

\begin{abstract}
"si no fuera porque ha habido en el país cierta tolerancia consciente o inconsciente por parte de los organismos que tienen a su cargo la supervigilancia de las compañías de seguros, a esta hora no habríamos superado la etapa de los seguros de incendio o de naufragio (...) El caso fortuito es incompatible con la noción de culpa..."2.
\end{abstract}

\title{
1.2. Caracteristicas del Contrato
}

Cabe ahora reflexionar sobre la conveniencia de eliminar como lo hace el proyecto, las características del contrato de seguros señaladas en el art. 1036 del Código de Comercio vigente, de acuerdo con el cual, el contrato de seguro es, consensual, bilateral, aleatorio y de tracto sucesivo.

Los atributos del contrato allí consignados delimitan bien la naturaleza del mismo. Si se quiere iniciar el título con una definición del contrato de seguro, no vemos problema, siempre que sea acertada, pero, derogar un artículo citado en decenas de sentencias de las altas Cortes porque señala con precisión las características del contrato y, por tanto, su sentido y alcance, no resulta, a nuestro modo de ver, una buena iniciativa.

La eliminación del artículo dará lugar a reflexiones como esta: ¿el contrato de seguro seguirá siendo consensual? Porque se elimina el art. 1036 que lo pasó de solemne a consensual y porque queda el 1046 que estaba vigente cuando era solemne, de acuerdo con el cual, el asegurador está obligado a entregar en original la póliza al tomador dentro de los quince días contados a partir de su celebración. Allí quedan tres solemnidades: a) debe haber una póliza b) lo que significa que debe ser escrito y c) la póliza debe ser entregada. Estos conceptos no se avienen con los contratos consensuales, donde basta el simple cruce de voluntades para que el contrato nazca a la vida jurídica.

Igualmente, al quedar eliminada la característica de ser aleatorio, volverán las discusiones sobre si en realidad el contrato de seguro es aleatorio, porque no es claro que haya falta de equivalencia en las prestaciones esperadas dado que por el desarrollo de la actuaría se sabe con alguna certeza el comportamiento de la siniestralidad y por lo mismo tal falta de equivalencia queda en duda.

\section{INTERPRETACIÓN DEL CONTRATO DE SEGURO}

Incluye el proyecto en el art. 1418 un aspecto novedoso: pautas para la interpretación del contrato de seguro, las cuales son:

- En los amparos y exclusiones no tendrá cabida la analogía, ni su interpretación extensiva.

\footnotetext{
2 Jaramillo C. (2013). Derecho de seguros. Bogotá: (eds.) Pontificia Universidad Javeriana - Facultad de Ciencias Jurídicas y Temis, Tomo II, p. 30.
} 
- Las condiciones o cláusulas particulares, prevalecerán sobre las condiciones o cláusulas generales. Igualmente, primarán las manuscritas respecto de las pre impresas, y también los anexos y demás documentos complementarios frente a las condiciones generales.

- En el evento de contradicción interna entre las condiciones generales, primarán las que, de acuerdo con la naturaleza específica del seguro celebrado y, en lo pertinente, con las circunstancias del caso individual, revelen de manera más fidedigna la finalidad atribuida al respectivo contrato, teniéndose en cuenta, en lo aplicable, la confianza legítima inculcada por el asegurador, y las expectativas razonables del tomador, asegurado, o beneficiario.

- Análoga regla se aplicará si la referida contradicción interna tiene lugar entre condiciones particulares.

- En caso de ambigüedad, o de duda objetivas, las condiciones del contrato se interpretarán en contra de que aquél que las definió.

Esperamos que estas directrices para una adecuada hermenéutica en la interpretación del contrato, contribuyan a dilucidar los problemas de interpretación que se presenten.

\section{LA PÓLIzA}

- El art. 1416 del proyecto hace un importante cambio: Elimina el primer inciso del art. 1046 del título V que dice así: "El contrato de seguro se probará por escrito o confesión". Quiere decir que la póliza se probaría por todos los medios probatorios contemplados en el Código General del Proceso. La prueba documental ya no se contraerá solamente a la póliza para probar el seguro, cualquier documento que genere certeza al juez servirá para probar la existencia del seguro, igual efecto generará la declaración de terceros o prueba testimonial.

- También elimina la parte inicial del segundo párrafo del art. 1046 que dice: "Con fines exclusivamente probatorios,", de manera que el primer inciso del actual art. 1046 queda sustituido por el 1416 en los siguientes términos: "El asegurador está obligado a entregar en su original al tomador, dentro de los quince días siguientes a la fecha de su celebración, el documento contentivo del contrato de seguro...".

- En cuanto a los datos que debe contener la póliza actualmente citados en el art. 1047 del C. de Co., el proyecto en su art.1417 introduce las siguientes modificaciones: a) sustituye el numeral 5 , sobre la identificación precisa de la cosa o persona con respecto a las cuales se contrata el seguro, por: "El interés que se asegura", modificación que no nos parece indispensable. b) Incluye dentro de las condiciones el nombre o razón social del intermediario de seguros, cuando este interviene o participa en el asesoramiento o en la colocación del respectivo seguro. c) En el parágrafo 2 del art. 1417, incluye una serie de aspectos tuitivos para el asegurado, estableciendo también sus deberes en el contrato, es así como manda que las condiciones generales y particulares 
que liberen la responsabilidad del asegurador, o la atenúen, deberán aparecer en caracteres destacados. Y le asigna a la autoridad competente velar por la observancia recíproca de los deberes de obrar de buena fe, de no abusar de los derechos propios y ajenos, de información razonable, de transparencia, de claridad, de cooperación o colaboración, de no sorprender y de coherencia y no contradicción ${ }^{3}$.

- $\quad$ Al art. 1049 de nuestra actual codificación que se refiere a los anexos y la renovación de la póliza, le agrega un parágrafo para distinguir entre la prórroga y la renovación, dice que la primera consiste en una extensión de la vigencia del contrato de seguro por el término estipulado, o en su defecto por el original y la segunda supone la celebración de un nuevo contrato.

- En cuanto a uno de los artículos más debatidos cuando entró en vigor el Código de Comercio vigente, el 1053, que regula el mérito ejecutivo de la póliza de seguros, le introduce el proyecto dos reformas, de una parte, pasa el plazo que tiene el asegurador para objetar de un mes a treinta días, es decir, lo deja como era originalmente; la Ley $\mathrm{N}^{\circ} 45$ de 1990, modificó este plazo a un mes. De quedar así la reforma, las compañías de seguros contarán con unos días más para estudiar las reclamaciones.

\section{EL RIESGO}

\subsection{Definición del riesgo}

El art. 1424 del proyecto define el riesgo así:

"El riesgo es el suceso incierto que no depende exclusivamente de la voluntad del tomador, del asegurado o del beneficiario, y cuya realización da origen a la obligación del asegurador. Los hechos ciertos, salvo la muerte, y los físicamente imposibles no constituyen riesgos. Tampoco constituye riesgo la incertidumbre subjetiva respecto de determinado hecho que haya tenido o no cumplimiento.

Lo anterior sin perjuicio de lo dispuesto para los seguros de responsabilidad, manejo y riesgos financieros".

Este último inciso es nuevo.

\subsection{Actos inasegurables}

El art. 1426 del proyecto permite el aseguramiento del suicidio de acuerdo con lo estipulado en la póliza, dice así el mencionado artículo: "El dolo y los actos meramente potestativos del tomador, asegurado o beneficiario no asegurables, por tanto una esti-

\footnotetext{
3 Palacios F. (2016). "El derecho de consumo y la protección al consumidor de seguros". En: Seguros tema esenciales. Bogotá, (eds.) Ecoe y Universidad de La Sabana, 4 edición, p. 17.
} 
pulación en tal sentido no producirá efecto alguno, sin perjuicio de lo estipulado para el suicidio...".

Con esta precisión, debe terminar el tortuoso debate sobre la asegurabilidad del suicidio, pues se ha sostenido por una parte de la doctrina que la auto eliminación de la vida no es asegurable, porque el riesgo es el suceso incierto que no depende exclusivamente de la voluntad del tomador, asegurado o beneficiario, tal como dispone el art. 1054 y porque el art. 1055 señala que son inasegurables los actos meramente potestativos del tomador, asegurado o beneficiario. Además, regula el tema en el art. 1529 del proyecto.

\subsection{Actos asegurables}

El último inciso del artículo del art. 1426 dispone que: "Serán asegurables los actos dolosos o meramente potestativos causados por las personas de las que es civilmente responsable el asegurado o por sus dependientes o subordinados".

El amparo del dolo y de los actos meramente potestativos, así sea, para las personas de las que es civilmente responsable el asegurado, los consideramos ajenos a los límites legales y técnicos del aseguramiento. Amparar todo lo que quiera hacer quien es sujeto del mismo, se opone a la incertidumbre que debe tener el riesgo.

Dice el Maestro Ossa al respecto: "Los actos meramente potestativos... es elemental que no puede haber riesgo allí donde la sola voluntad del asegurado pudiera desencadenar el evento asegurado. De ahí la calificación de estos actos como "meramente potestativos"4.

\subsection{Debe existir relación de causa a efecto entre la preexistencia y el siniestro}

El art. 1429 regula la relación de causa a efecto entre la preexistencia y el siniestro. El art. 1058 del título V no la contempla. Mediante sentencia de constitucionalidad del 15 de mayo de 1997, cuyo magistrado ponente fue el doctor Jorge Mejía Arango, se determinó que no se requiere un nexo de causalidad ente el hecho respecto del cual se predica la reticencia o inexactitud y el siniestro.

El tema, presentado a través de un ejemplo, puede sintetizarse así: ¿si el tomador no declara al momento de tomar el seguro tener diabetes, pero su deceso se produce por un accidente, o por otra enfermedad que nada tenga que ver con la diabetes, ¿se debe pagar el seguro? Al respecto hay dos posiciones antagónicas, de una parte, la que se basa en los requisitos para la validez de los contratos entre los que se cuenta el consentimiento de las partes que debe ser exento de error, fuerza o dolo, de no estarlo, el acto jurídico adolece de nulidad relativa. La reticencia en la declaración del tomador, al ser un dolo negativo, genera la nulidad relativa del contrato de seguro.

4 Ossa J. (1991). Teoría general del seguro. El contrato. Bogotá, Temis 2 edición, p. 107. 
Y, de otra parte, la que sostiene la Corte Constitucional en la sentencia T-82 del primero de junio de 2016 al resolver una tutela presentada por una beneficiaria en un seguro de vida grupo deudores, en el cual, entre otros amparos, se cubría la incapacidad total y permanente. La accionante sufrió un accidente cerebro vascular con pérdida del $78.85 \%$ de su capacidad laboral, según calificación de la Junta de Calificación de Invalidez respectiva, sin embargo, el seguro fue negado por no haber declarado al tomar el seguro que había sido sometida a una cirugía de columna lumbar.

La Corte Constitucional consideró en su fallo que "la decisión deliberada, arbitraria y abusiva de negar el pago del seguro, sin acreditar debidamente la relación de causalidad entre la preexistencia alegada y la ocurrencia del siniestro, devino en la vulneración del derecho al debido proceso de la accionante... ${ }^{5 "}$.

Resulta evidente que los autores del proyecto toman partido por la línea que marca la precitada sentencia, cuando en el art. 1429 dice: "El asegurador no podrá aducir, válidamente, la nulidad relativa del seguro en aquellas situaciones en las que la reticencia, o la inexactitud, según fuere el caso, no tuvieron ninguna incidencia causal en la realización del riesgo asegurado".

\subsection{La agravación del riesgo}

El art. 1431, que equivale al 1060 de nuestra legislación vigente, incluye una nueva regulación en los casos en que no se haya dado noticia al asegurador de la agravación del estado del riesgo. El art. 1060 prevé que cuando no se produce la notificación oportuna de la agravación del riesgo, se genera la terminación del contrato, al paso que el art. 1431 dice que se produce la resolución de pleno derecho. Finalmente, regula una nueva situación y es la que se refiere al evento de cuando la agravación del estado del riesgo carece de incidencia frente a éste, en tal caso no se producirá la resolución de pleno derecho del contrato y el asegurador puede deducir directamente del monto de la indemnización el valor proporcional equivalente al mayor valor de la prima que, de manera razonable, hubiere podido exigir en el evento de haber sido informado de manera oportuna sobre dicha agravación.

\subsection{La garantia}

La garantía es la promesa en virtud de la cual el asegurado se obliga a hacer o no determinada cosa, o a cumplir determinada exigencia, o mediante la cual afirma o niega la existencia de determinada situación de hecho, así reza el art. 1061 de nuestro Estatuto Mercantil vigente.

La garantía según el tercer inciso del precitado artículo sea o no sustancial respecto del riesgo, deberá cumplirse estrictamente. En caso contrario el contrato será anulable. El art. 1434 del proyecto hace menos exigente la situación para el asegurado,

\footnotetext{
5 Palacios F. (2018). Estudios sobre Derecho de Seguros, homenaje al profesor Andrés Eloy Ordóñez. Bogotá: Universidad Externado de Colombia, p. 318.
} 
pues, dice que "la garantía deberá cumplirse cabalmente" y ya no exige que "sea o no sustancial al riesgo deberá cumplirse estrictamente."

El mismo artículo trae una novedad en cuanto que permite por convención que no se aplique la agravación del riesgo a los amparos accesorios en los seguros de vida.

\subsection{La reticencia}

\subsubsection{La omisión o inexactitud debe ser sobre hechos relevantes o sustanciales}

Esto es que al tomador le corresponde declarar sobre hechos significativos en relación con el estado del riesgo, no cualquier omisión puede generar la nulidad relativa, debe ser importante, "relevante", "sustancial", cumpliéndose estas características, el asegurador podrá objetar la reclamación por nulidad relativa. Estas características, si bien no se encuentran en la normativa vigente, si venían siendo citadas en la doctrina y la jurisprudencia.

La inexistencia o la inexactitud deben ser apreciadas de manera razonable por el asegurador. Conocida la inexistencia o la inexactitud por el asegurador, éste debe abordar el examen de la situación de manera razonable para determinar si lo hubieren retraído de celebrar el contrato, o estipulado condiciones más onerosas. La expresión "razonablemente" no hace parte del actual art. 1058 del Código de Comercio.

\subsubsection{Sanción cuando el tomador no llena un espacio en la solicitud y se celebra el contrato}

Es otro aspecto nuevo: tampoco será procedente la nulidad, en caso de que los hechos o circunstancias que determinan el estado del riesgo, que se consignaron expresamente en el cuestionario contentivo de las preguntas formuladas por el asegurador al tomador, no fueron respondidas por éste y pese a ello, aquél celebró el contrato.

\subsubsection{Eliminación del error inculpable}

Elimina el concepto de error inculpable, que no aparece regulado como lo hace actualmente el art. 1058; figura que no permite que el contrato sea nulo cuando en la declaración del tomador no hay asomo de duda sobre su actuar, por ejemplo, cuando declara no haber sufrido patologías del corazón, sin embargo, estudiado el caso, se encuentra que había tenido infartos silenciosos, en casos como éste el asegurador sólo está obligado a pagar un porcentaje de la prestación asegurada, equivalente al que la tarifa o la prima estipulada en el contrato representa equivalente al que la tarifa o la prima estipulada en el contrato represente respecto del tarifa o la prima adecuada al verdadero estado del riesgo. 


\title{
4.7.4. Abrogación de las distintas graduaciones de las culpas
}

El art 1058 vigente contempla una graduación de culpas en el primer, segundo y tercer incisos, en el primero, prevé la existencia de cuestionario, en este caso basta la existencia de reticencia o error del tomador para que el contrato adolezca de nulidad relativa, siempre que tales conductas de haberlas conocido el asegurador lo hubieren retraído a celebrar el contrato o inducido a estipular condiciones más onerosas.

Luego hace otras graduaciones de la culpa con distintas consecuencias, si la declaración no se hace con sujeción a un cuestionario, o si la inexactitud o la reticencia provienen de error inculpable del tomador. Estas graduaciones las excluye el proyecto.

\subsubsection{Obligación de mantener el estado del riesgo}

Al igual que el art.1060 de nuestro Código de Comercio vigente, el art. 1431 del proyecto mantiene la obligación para el asegurado o el tomador, según sea el caso, de mantener el estado del riesgo en los seguros de daños, pero introduce algunas modificaciones: a) La falta de notificación oportuna de la agravación del riesgo produce según el art. 1060 la terminación del contrato, en el proyecto se contempla una figura distinta de no haber notificación de la agravación, cual es la resolución de pleno derecho del contrato.

La terminación en el título V del libro IV del Código de Comercio vigente se utiliza a lo largo del mismo cuando hay incumplimiento de las obligaciones por parte de alguno de los extremos contractuales ${ }^{6}$, ahora se rompe esta línea y en vez de terminación se utiliza resolución de pleno derecho del contrato, cuando hay incumplimiento de las obligaciones por una de las partes.

En cuanto a la terminación, dice la exposición de motivos del proyecto del año 58 al referirse a este tema,

\begin{abstract}
“Terminación: Es equivalente a la resolución en los contratos de ejecución instantánea y adopta esa denominación en los contratos de tracto sucesivo. Se da como consecuencia del incumplimiento de las obligaciones por una de las partes, el no pago de la prima, por ejemplo"7.
\end{abstract}

b) Agrega el art. 1431 del proyecto que “...si no se da la noticia a que se refiere el art. 511 y se produce el siniestro, la agravación del estado de riesgo que carece de incidencia frente a éste no producirá la resolución de pleno derecho del contrato...".

\subsubsection{Disminución del riesgo por causas sobrevinientes}

El art. 1065 del Código de Comercio vigente regula la disminución del riesgo, artículo que ha estado muy en boga con motivo de la pandemia y la disminución del riesgo en

\footnotetext{
${ }^{6}$ Ossa J. (1991). Teoría general del seguro. El contrato. Bogotá, Temis, 2 edición, p. 502.

7 Ibíd., apéndice, p. 555.
} 
algunos ramos como el de automóviles. El art. 1065 del C. de Co. Vigente dice que, en caso de disminución del riesgo, el asegurador deberá reducir la prima estipulada, según la tarifa correspondiente, por el tiempo no corrido del seguro.

El art. 1432 del proyecto maneja el tema de manera distinta, dice que el tomador del seguro o el asegurado, con posterioridad a la celebración del contrato, podrán poner en conocimiento del asegurador las circunstancias sobrevinientes que objetivamente han disminuido el riesgo asegurado, que sean de tal relevancia que, si hubieren sido conocidas por éste en el momento de la referida celebración, razonablemente lo habría celebrado en condiciones más favorables, respecto de aquéllos.

El art. 1433 dice que cuando sobrevengan circunstancias extraordinarias e imprevisibles que en forma inequívoca agraven o disminuyan masiva y generalizadamente el estado de riesgo originario, las autoridades administrativas competentes podrán solicitar del asegurador que adopte las medidas razonables para restablecer oportunamente el equilibrio contractual alterado, en lo que resulte procedente.

\section{LA PRIMA}

Solo comentaremos dos cambios importantes: a) El plazo para el pago pasa de un mes a 30 días, b) La mora en el pago de la prima o de los certificados o anexos que se expidan con fundamento en ella, produce la suspensión del contrato, no la terminación automática, como lo prevé el art 1068. Por lo tanto, de acuerdo con el art. 1440 del proyecto basta que el tomador o asegurado paguen la prima adeudada para que la cobertura se restablezca. Queda claro que, si el siniestro acontece durante la suspensión de la cobertura, el asegurador no adeudará prestación alguna.

\section{LA REVOCACIÓN DEL CONTRATO DE SEGURO}

Mantiene el concepto del art.1071 del C. de Co. vigente en cuanto que el contrato puede ser revocado unilateralmente por cualquiera de las partes, también son revocables la póliza flotante y la automática, pero agrega que salvo para trayectos en curso. Agrega que tampoco procede la revocación en los seguros de cumplimiento, y mantiene la excepción para los seguros de vida.

\section{EL SINIESTRO}

Al igual que el art. 1072, el proyecto en su art. 1444 pregona que se denomina siniestro la realización del riesgo asegurado. El art. 1446 del proyecto crea una nueva obligación para el asegurador en los siguientes términos: "Cuando el tomador, asegurado o beneficiario alleguen toda la documentación requerida para que válidamente pueda realizarse la transferencia del salvamento al asegurador, éste no podrá negarse, de 
manera injustificada, al reconocimiento de la prestación a su cargo". Sin duda que en la exposición de motivos debe aclararse la razón y alcance de este inciso.

\section{LA CARGA DE LA PRUEBA}

El art. 1077 señala que corresponderá al asegurado demostrar la ocurrencia del siniestro, así como la cuantía de la pérdida. Y al asegurador le incumbe demostrar los hechos o circunstancias excluyentes de su responsabilidad. El proyecto dice que el asegurado debe cumplir con estas obligaciones "en forma razonable", acompañando la reclamación al asegurador aún de forma extrajudicial.

Agrega que el asegurador deberá observar, desde el momento en que conozca por cualquier medio la existencia del siniestro, una conducta prudente y cooperante para la acreditación de la pérdida que está en cabeza del asegurado, en cuanto resulte procedente.

La modificación es susceptible de una crítica positiva y otra negativa, la primera en cuanto crea un nuevo deber para el asegurador que es la de asumir una conducta prudente y cooperante para la acreditación de la pérdida, y la segunda en cuanto que la acreditación de la pérdida que actualmente es muy clara en el art. 1077 que la pone en cabeza del asegurado, ahora deja la posibilidad de que sea él en cuanto resulte procedente. Sin duda la segunda parte creará un caos jurídico, pues se suscitarán discusiones si la acreditación de la pérdida corresponde al asegurado o no.

\section{EL PAGO DE LA INDEMNIZACIÓN}

El art.1080 vigente, regula lo relacionado con el pago de la indemnización, son cuatro incisos largos, el proyecto divide este artículo en varios y le introduce modificaciones. Es así como el art. 1450 dice que el asegurador está obligado a satisfacer la prestación a su cargo dentro de los treinta siguientes a la fecha en que el beneficiario o asegurado presente la reclamación. Dentro de este término podrá objetarlas por razones serias y fundadas, dando la información en que se concrete.

Cambia el término de un mes por el de treinta días para pagar la prestación a su cargo, contados desde cuando el beneficiario presente la reclamación. Vuelve a la terminología que la Ley N 45 de 1990 le había dado al mérito ejecutivo de la póliza de seguros, en cuanto que exigía que la objeción en estos casos debía de ser seria y fundada, que fue eliminada por el Código General del Proceso. De manera que la objeción vuelve a quedar con estas características, pero ya no para cuando se trate de la acción ejecutiva en seguros, sino como característica general que deben tener todas las objeciones.

\subsection{Potestad para designar un perito de mutuo acuerdo}

El art. 1451 permite que las partes de común acuerdo puedan designar de mutuo acuerdo un perito que se encargue de establecer las causas y el origen del siniestro, y 
el importe y la forma de la indemnización, cuya determinación será obligatoria para las partes.

En relación con el experto de que trata el art. 1451, seguramente será necesaria la reglamentación del artículo para saber quién o quienes pagan los honorarios y las calidades profesionales y morales que deben tener tales expertos.

\section{PRINCIPIOS COMUNES A LOS SEGUROS DE DAÑOS}

\subsection{Los seguros paramétricos}

En el art. 1463 incorpora un seguro que no existe en nuestra legislación actual: los seguros paramétricos, dice que en éstos la indemnización se determinará en función de la variación del parámetro pactado como riesgo asegurado y de conformidad con los valores estimados en la póliza.

\subsection{La regla proporcional}

En relación con el infraseguro, agrega en el art. 1473, que éste no se aplicará al seguro de cumplimiento ni al seguro de responsabilidad.

\subsection{Inclusión del seguro de cumplimiento y de manejo}

En el título XXXIV que equivale al título V del libro IV de nuestro Código de Comercio vigente, con todas las reformas que le introduce el proyecto, incluye un nuevo seguro, el de cumplimiento, actualmente se encuentran regulados los seguros de Incendio, transporte, responsabilidad y reaseguro.

El art. 1499 dice:

"Por el seguro de cumplimiento el asegurador se obliga, dentro de los límites establecidos en la ley y en el contrato, en caso de incumplimiento por el tomador del seguro de sus obligaciones legales o contractuales, a indemnizar al asegurado a título de resarcimiento o penalidad los daños patrimoniales sufridos.

Será necesaria la autorización expresa del asegurado para resolver el contrato de seguro de cumplimiento por causas distintas al mero transcurso del plazo de duración establecido".

El art. 1500 señala lo siguiente sobre el seguro de manejo:

"El seguro de manejo tiene por objeto indemnizar al asegurado por las pérdidas derivadas de los actos fraudulentos de sus empleados y demás actos que indique la ley.

El seguro de manejo y riesgos financieros tiene por finalidad el amparo de los riesgos propios de la actividad financiera, pudiéndose circunscribir el riesgo asegurado al descubrimiento de pérdidas durante la vigencia, así se trate de hechos ocurridos con anterioridad a su iniciación, cuya ocurrencia es desconocida por el tomador y por el asegurador". 


\section{SEGURO DE VIDA INDIVIDUAL}

Gran polémica ha causado la jurisprudencia de la Corte Constitucional por fallos de revisión de tutelas en seguros de vida grupo deudores, de acuerdo con los cuales, si la aseguradora no ordena examen médico al tomador, no podrá luego alegar nulidades por error o reticencia, no obstante que el art. 1158 del Código de Comercio dice que, aunque el asegurador prescinda del examen médico, el asegurado debe cumplir con la declaración sincera que le exige el art. 1058.

Se requiere, sin lugar a dudas una solución por vía legislativa sobre este asunto y el proyecto la contempla en el art. 1534, el cual mantiene la obligación para el asegurado de cumplir con las obligaciones de hacer una declaración de acuerdo con el art. 1429 del proyecto, pero agrega que el asegurador no podrá alegar la reticencia por la no declaración de preexistencias médicas si, teniendo la posibilidad para ello, no solicita exámenes médicos al momento de celebrar el contrato o no realiza las averiguaciones oportunas y razonables para establecer el estado actual del riesgo.

\section{CONCLUSIONES}

Encontramos en el proyecto, aspectos positivos y otros que merecen mayor reflexión por parte de los autores para introducirle cambios que, en nuestra opinión, son necesarios.

Aspectos favorables del proyecto:

- Consigna pautas o directrices para interpretar el contrato de seguro.

- El contrato de seguro se podrá probar por todos los medios probatorios y no solamente por la póliza y la confesión.

- La mora en la prima no produce la terminación automática del contrato, sino la suspensión.

- La garantía en el contrato de seguro queda regulada de manera más benigna hacia el asegurado.

- Define situaciones que han generado gran debate y que requerían solución legislativa: El examen médico antes de otorgar el seguro.; la asegurabilidad del suicidio; y determinar si debe haber una relación de causa a efecto entre la preexistencia y el siniestro.

- El deber para el asegurador de asumir una conducta prudente y cooperante para la acreditación de la pérdida.

- La incorporación de la compañera o compañero permanente del asegurado como beneficiarios cuando no se designe beneficiario, o la designación se haga ineficaz o quede sin efecto por cualquier causa. 
Es indispensable revisar los siguientes aspectos:

- $\quad$ La definición que contiene sobre el contrato de seguro.

- $\quad$ La eliminación de las características del contrato de seguro.

- El amparo de los actos meramente potestativos causados por las personas de las que es civilmente responsable el asegurado.

- La obligación para el asegurador de pagar la prestación de su obligación cuando el tomador, asegurado o beneficiario alleguen la documentación requerida para realizar la transferencia del salvamento.

- Aclarar a quien corresponde la acreditación de la pérdida, pues el proyecto señala que está en cabeza del asegurado en cuanto resulte procedente.

- Debe aprovecharse la eventual reforma para regular el seguro de lucro cesante y el de arrendamientos, que han dado lugar a distintas interpretaciones con motivo de los siniestros que se generaron en estos seguros a causa de la pandemia.

\section{BIBLIOGRAFÍA}

Jaramillo C. (2013). Derecho de seguros. Bogotá. (eds.) Pontificia Universidad Javeriana-Facultad de Ciencias Jurídicas y Temis, tomo II, p. 30.

Ossa J. (1991). Teoría general del seguro. El contrato. Bogotá, Temis, 2 edición, p.1.

Ossa J. (1991). Teoría general del seguro. El contrato. Bogotá, Temis 2 edición, p.107.

Ossa J. (1991) . Teoría general del seguro. El contrato. Bogotá, Temis 2 edición, p.502.

Palacios F. (2016). "El derecho de consumo y la protección al consumidor de seguros". En: Seguros tema esenciales. Bogotá, (eds.) Ecoe y Universidad de La Sabana, 4 ed. p. 17.

Palacios F. (2018). Estudios sobre Derecho de Seguros, homenaje al profesor Andrés Eloy Ordóñez. Bogotá: Universidad Externado de Colombia, p. 318.

Proyecto de Código Civil, Universidad Nacional de Colombia, primera versión. http: //derecho. bogota.unal.edu.co/proyecto-de-actualizacion-del-codigo-civil/. 
